Article

\title{
Added and Free Sugars Intake and Metabolic Biomarkers in Japanese Adolescents
}

\author{
Masayuki Okuda ${ }^{1, *(\mathbb{D}}$, Aya Fujiwara ${ }^{2,3}$ and Satoshi Sasaki ${ }^{3}$ \\ 1 Graduate School of Sciences and Technology for Innovation, Yamaguchi University, 1-1-1 Minami-Kogushi, \\ Ube 755-8505, Japan \\ 2 Department of Nutritional Epidemiology and Shokuiku, National Institute of Biomedical Innovation, \\ Health and Nutrition, 1-23-1 Toyama, Shinjuku-ku, Tokyo 162-8636, Japan; fujiwaraay@nibiohn.go.jp \\ 3 Department of Social and Preventive Epidemiology, Graduate School of Medicine, and School of Public \\ Health, The University of Tokyo, 7-3-1 Hongo, Bunkyo-ku, Tokyo 113-0033, Japan; stssasak@m.u-tokyo.ac.jp \\ * Correspondence: okuda@yamaguchi-u.ac.jp; Tel.: +81-836-22-2231
}

Received: 4 June 2020; Accepted: 7 July 2020; Published: 9 July 2020

check for updates

\begin{abstract}
Reduction in the intakes of added and free sugars is a recommendation to lower cardiometabolic risks. Sugars intake is considered lowest in the Asian-Pacific region, particularly Japan. We examined the association between sugars intake and cardiometabolic risks in Japanese adolescents. We included 3242 students (mean age, 13.56 years) living in Shunan City, Japan, between 2006 and 2010. Sugars intake was estimated using the brief-type self-administered diet history questionnaire. Anthropometrics, serum lipids, fasting plasma glucose, and blood pressure were measured. Metabolic syndrome was determined by the combination of overweight and other risks. Intakes of added and free sugars were $7.6-7.9 \% \mathrm{E}$ and $8.4-8.8 \% \mathrm{E}$ of the total energy intake (\%E), respectively. Categories based on quintiles of added or free sugars intakes were associated with fasting glucose, systolic blood pressure, and the $z$-score of metabolic syndrome $\left(P_{\text {trend }} \leq 0.025\right)$. Other than the association between added sugars $\geq 10 \% \mathrm{E}$ and high glucose (odds ratio $1.51,95 \%$ confidence interval 1.04-2.19, $p=0.031$ ), non-significantly high intakes of added or free sugars for risks occurred. Association was observed between added or free sugars intake and cardiometabolic biomarkers in Japanese adolescents, and added sugars intake $<10 \% \mathrm{E}$ could prevent glucose intolerance but not metabolic syndrome.
\end{abstract}

Keywords: added sugars; adolescents; cardiovascular risks; free sugars; Japanese; metabolic syndrome

\section{Introduction}

Excess intake of sugars is associated with increased prevalence of obesity [1], cardiometabolic risks [2], and dental caries [3]. Free sugars are defined by the World Health Organization (WHO)/Food and Agriculture Organization (FAO) as all monosaccharides and disaccharides added to foods by manufacturers, cooks or customers, and sugars naturally present in honey, syrups, and fruit juices [4]. The WHO recommends intake of free sugars $<10 \%$ of the total energy intake (TEI) and advises the reduction of free sugars to $<5 \%$ of TEI [4]. Added sugars are defined as sugar and syrups added to food during processing and preparation, excluding sugars that occur naturally in foods [5]. The 2015 US Dietary Guidelines recommend keeping added sugars intake to $<10 \%$ of TEI [6]. The American Heart Association recommends that added sugars in children be limited to $\leq 25 \mathrm{~g} /$ day [7], which corresponds to $5 \%$ of TEI for those who consume $2000 \mathrm{kcal} /$ day.

Obesity and related cardiovascular diseases are a public health burden in Japan as well as in American and European countries [8]. However, among the member countries of the Organization for 
Economic Co-operation Development (OECD), Japan has the lowest prevalence of obesity [9]. Moreover, recently, Japan has not witnessed an increase in the prevalence of diabetes and prediabetes [10], and the prevalence of childhood obesity has decreased since 2002 [11]. Asians are likely to suffer from diabetes at a relatively low body mass index (BMI) or waist circumference in comparison to Europids [12-14], and fat distribution varies among Asian countries [15]. It should be clarified whether added or free sugars could pose additional cardiometabolic risks for Japanese people.

Japan has the lowest sugar consumption per capita among the developed OECD countries [16]. In the US and UK, the main source of added sugars, especially for adolescents, includes liquid sugars such as sugar-sweetened beverages (SSBs), and sports drinks $[17,18]$. However, consumption of SSBs in the Asia-Pacific region is the lowest in the world [19]. Further, Japanese use sugar as a seasoning agent in cooking modern Japanese cuisine "washoku" [20].

There have been few studies investigating the association between intake of sugars or SSBs and cardiovascular risks among Asian adolescents. Studies on adolescents from Korea [21], China [22], Japan, and Cambodia [23] examined the association of sugars intake with body fatness, while studies from Korea [24] and Iran [25] examined the association with metabolic risk factors, and showed no significant associations. Therefore, the aim of this study was to examine the association between added or free sugars intake and metabolic biomarkers other than adiposity in Japanese adolescents and to evaluate high intake of sugars to identify adolescents with cardiometabolic risks. In meta-analyses on energy-control trials mostly from Europe and the USA [1,26], observed effects of sugars intake on body weight, blood pressure (BP), and blood lipid profile are considered via an excess of energy intake in conjunction with an excess of sugars intake; so we examined the associations with adjustment for TEI.

\section{Materials and Methods}

\subsection{Subjects}

This study was part of the Shunan Child Cohort Study described elsewhere in detail [27,28]. Data of the 8th graders attending 17 secondary schools in Shunan City, Japan, between 2006 and 2010 were used. Students who assented and whose guardians provided written informed consent were asked to complete questionnaires, take a blood test, and have anthropometrics and BP measured. This study protocol was in accordance with the Declaration of Helsinki and approved by the Ethics Committee of Yamaguchi University Hospital (H17-14 on 18 May, 2005, H17-14-2 on 22 March, 2006, H22-158 on 26 January, 2011, and H22-158- [1] on 22 March, 2017) and the education board of Shunan City.

\subsection{Dietary Assessment}

Dietary intake of the students during the last month was assessed using the brief type of self-administered diet history questionnaire for youths (BDHQ15y), which was validated with biomarkers such as carotenoids, tocopherols, fatty acids, and urea nitrogen $[29,30]$. Nutrition intake estimated from the BDHQ for adults has been validated in comparison with those estimated from dietary records [31]. Sugars intake was estimated using a food composition database developed for Japanese sugars intake [32]. Estimation of added and free sugars from the BDHQ for adults was validated in comparison with the 16-day dietary records (Spearman's correlation coefficients, 0.40-0.57) [33]. Intakes of sugars, fat, and total dietary fiber were expressed as energy density (percentage of TEI, \%E, or $\mathrm{g} / 1000 \mathrm{kcal})$; fat and total dietary fiber intake has been described elsewhere [28].

\subsection{Blood Tests}

The students were requested to restrict intake of any foods or beverages from $10 \mathrm{p} . \mathrm{m}$. on the day before blood drawing, which was performed after 9 a.m. at school. Whether the students took breakfast or not before blood drawing was recorded. Levels of low-density lipoprotein cholesterol (LDL), high-density lipoprotein cholesterol (HDL), triglyceride (TG), and plasma glucose (Glu) were analyzed at the clinical laboratory of Tokuyama Medical Association Hospital. 


\subsection{Anthropometrics and Blood Pressure}

Body height and weight in units of $0.1 \mathrm{~cm}$ and $0.1 \mathrm{~kg}$, respectively, were measured while wearing light cloths and barefoot at school. BMI was calculated as weight $(\mathrm{kg}) /$ height $(\mathrm{m})^{2}$. BP was measured using an automated sphygmomanometer (HEM-707, HEM-757, or HEM-780, OMRON) after 5 min of sitting, before drawing blood.

\subsection{Analytic Variables}

The students were categorized into five groups using gender-specific quintiles of added or free sugars intakes. In addition, dichotomous variables of added and free sugars intake were created based on whether each sugars intake was $\geq 5 \% \mathrm{E}$ or not, and whether $\geq 10 \% \mathrm{E}$ or not. A z-score of BMI (zBMI) was calculated using the LMS (Lambda-Mu-Sigma) method with the 1979-1981 Japanese reference [34]. Overweight, including obesity, was defined using BMI cutoffs of the International Obesity Task Force (IOTF) criteria, which corresponds to BMI of $25 \mathrm{~kg} / \mathrm{m}^{2}$ at 18 years old [35], or as $\geq 1$ standard deviation (SD) [36]. High risks were defined as LDL $\geq 120 \mathrm{mg} / \mathrm{dL}$ [37], HDL $<40 \mathrm{mg} / \mathrm{dL}, \mathrm{TG} \geq 150 \mathrm{mg} / \mathrm{dL}$, Glu $\geq 100 \mathrm{mg} / \mathrm{dL}$, and high BP (systolic BP $\geq 130 \mathrm{mmHg}$ or diastolic BP $\geq 85 \mathrm{mmHg}$ ) [38]. Adolescent metabolic syndrome was defined as overweight instead of abdominal adiposity plus two risks of low HDL, high TG, high Glu, and high BP with the modified International Diabetes Federation (IDF) definition [38]. A continuous standardized variable of metabolic syndrome was calculated in accordance with a previous report [39] from the 6 following measurements used for the adolescent metabolic syndrome definition: zBMI, and the natural logarithmic transformed HDL, TG, Glu, SBP, and DBP (the z-score of HDL was inversed). As confounding factors, questions on sleeping duration (hr), number of siblings $(1,2$, or $\geq 3$ ), single parent, and physical activity ( $>2$ times of exercise per week) were asked in the lifestyle questionnaire, and described in elsewhere [28]. Ages (in years) were calculated as (the blood drawing date-the birth date)/365.25.

We excluded from the analysis the students with missing data, those who had diseases (heart disease, kidney disease, diabetes, hypertension), or implausible energy intake estimated from BDHQ (Figure 1). Plausible energy intake was $\geq 0.5$ times the energy requirement at physical activity level 1 , and $\leq 1.5$ times the energy requirement at physical activity level 3, according to the Dietary Reference Intake for Japanese people [40]. In addition, we excluded the students who took breakfast before blood drawing or had missing records about taking breakfast.

\subsection{Statistical Analysis}

We statistically analyzed the data of 3242 students using SAS 9.4 (SAS Institute Japan Inc., Tokyo, Japan). Continuous and categorical variables were expressed as mean \pm SD and as counts (\%), respectively. Cardiometabolic risk factors (continuous variables), among the five ranked categories of sugars intake were calculated as the least square means with adjustment for age, gender, sleeping duration, number of siblings, single parent, physical activity, TEI, fat, total dietary fiber, and zBMI, and tested for trends as a simple linear relationship $\left(P_{\text {trend }}\right)$. When zBMI was a dependent variable, zBMI was excluded from confounders. Odds ratios (ORs) of high sugars intake ( $\geq 5 \% \mathrm{E}$, or $\geq 10 \% \mathrm{E})$ for dichotomous variables of metabolic markers were adjusted for age, gender, sleeping duration, number of siblings, single parent, physical activity, TEI, fat, total dietary fiber and zBMI. ORs for overweight were adjusted for all confounders excluding zBMI. For the sensitivity analysis, we analyzed the data of students who had a fasting blood test $(n=3242)$ with other definitions of metabolic syndrome. Since the prevalence of metabolic syndrome was low in this sample, high risks were defined as the highest $10 \%$ of the risk parameters in this sample [41]. We additionally analyzed the data separately by gender ( $n$ for males $=1659$, and for females $=1583$ ). Since the validity of the dietary data of these students might be higher than that of the parents of the students who responded instead [29], we analyzed the data of the students who responded to the BDHQ15y by themselves $(n=1626)$, excluding the 
data in which their parents responded to it instead of the students, or if helped by them $(n=1616)$. The statistical test results were considered significant when $p$ values were $<0.05$.

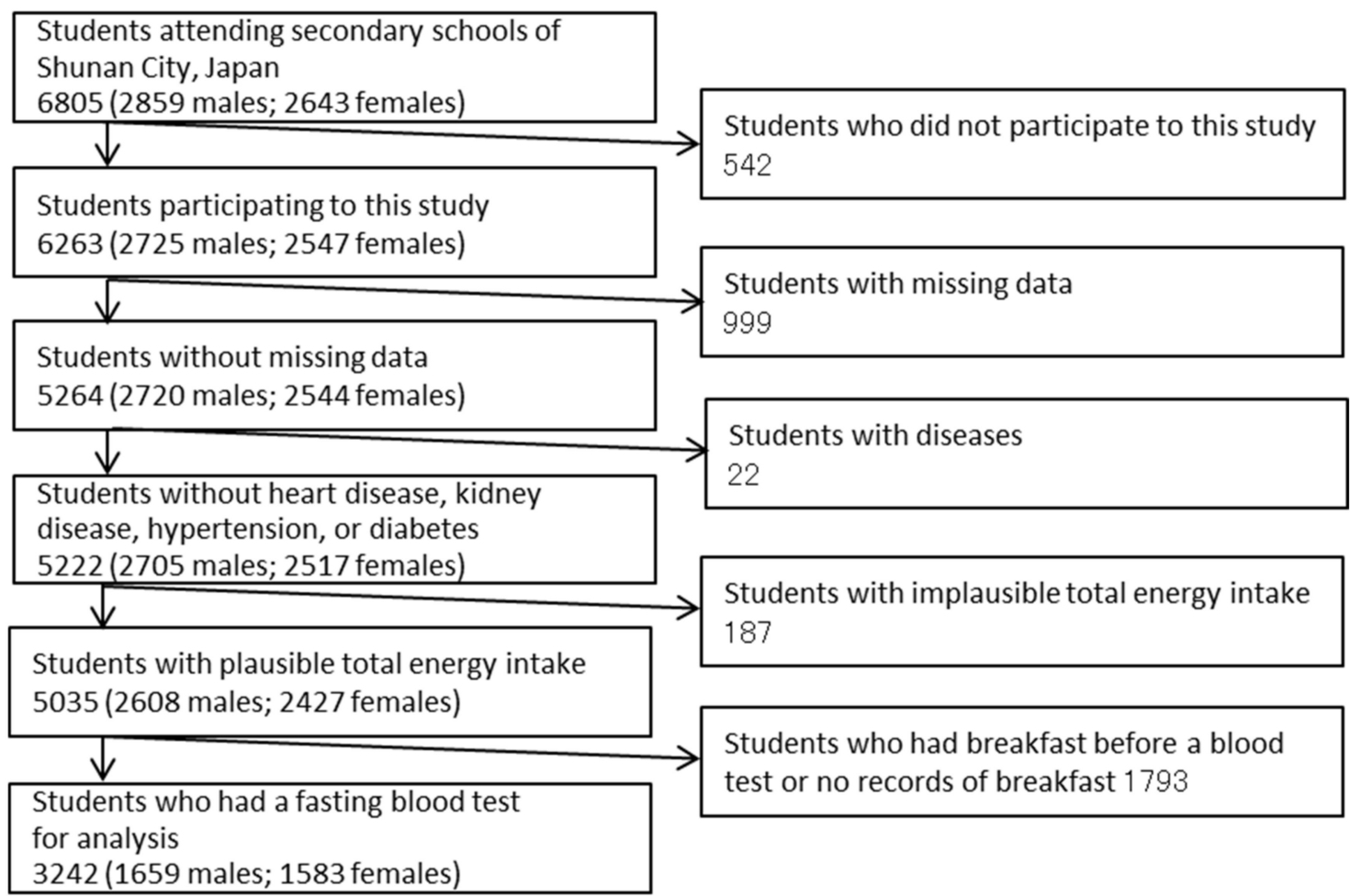

Figure 1. Subjects' selection.

\section{Results}

Of the 3242 students who had a fasting blood test, 1659 (51.2\%) were male. The students' mean (SD) age was $13.56 \pm 0.29$ years for both sexes, and the mean (SD) BMI was $18.95 \pm 2.70 \mathrm{~kg} / \mathrm{m}^{2}$ for males and $19.54 \pm 2.68 \mathrm{~kg} / \mathrm{m}^{2}$ for females (Table 1). The prevalence of overweight according to the IOTF was $154 / 1659(9.3 \%)$ in males and 148/1583 (9.4\%) in females, which were lower than those defined as $\geq 1$ SD (16.0\% (265/1659) in males and 19.4\% (307/1583) in females). The prevalence of metabolic syndrome was higher when using the $\geq 1$ SD definition for overweight than when using the IOTF definition.

Intakes of added and free sugars were as follows: males, $7.6 \pm 4.0 \% \mathrm{E}$, and $8.4 \pm 4.4 \% \mathrm{E}$; females, $7.9 \pm 4.1 \% \mathrm{E}$, and $8.8 \pm 4.6 \% \mathrm{E}$, respectively. Males who had high intakes of added sugars $\geq 5 \% \mathrm{E}$ or $\geq 10 \% \mathrm{E}$ accounted for $72.9 \%$ or $20.6 \%$ of the population, and females accounted for $78.0 \%$ or $22.1 \%$, respectively. Males with high intake of free sugars $\geq 5 \% \mathrm{E}$ or $\geq 10 \% \mathrm{E}$ accounted for $78.7 \%$ or $27.1 \%$ of the population and females accounted for $82.4 \%$ or $29.9 \%$, respectively. 
Table 1. Characteristics of the study participants.

\begin{tabular}{lcc}
\hline & Males, $\boldsymbol{n}=\mathbf{1 6 5 9}$ & Females, $\boldsymbol{n}=\mathbf{1 5 8 3}$ \\
\hline Age, years & $13.56 \pm 0.29$ & $13.56 \pm 0.29$ \\
BMI, kg/m ${ }^{2}$ & $19.0 \pm 2.7$ & $19.5 \pm 2.7$ \\
zBMI & $0.01 \pm 1.06$ & $0.13 \pm 1.07$ \\
Total energy, kcal/day & $2414 \pm 655$ & $2014 \pm 538$ \\
Carbohydrate, \%E & $55.3 \pm 6.7$ & $53.2 \pm 6.4$ \\
Added sugars, \%E & $7.6 \pm 4.0$ & $7.9 \pm 4.1$ \\
Free sugars, \%E & $8.4 \pm 4.4$ & $8.8 \pm 4.6$ \\
Overweight $(\mathrm{IOTF})$ & $154(9.3)$ & $148(9.4)$ \\
Overweight $(\geq 1 \mathrm{SD})$ & $265(16.0)$ & $307(19.4)$ \\
High LDL $(\geq 120 \mathrm{mg} / \mathrm{dL})$ & $122(7.4)$ & $166(10.5)$ \\
Low HDL $(<40 \mathrm{mg} / \mathrm{dL})$ & $20(1.2)$ & $8(0.5)$ \\
High TG $(\geq 150 \mathrm{mg} / \mathrm{dL})$ & $34(2.1)$ & $27(1.7)$ \\
High Glu $(\geq 100 \mathrm{mg} / \mathrm{dL})$ & $106(6.4)$ & $97(3.0)$ \\
High SBP $(\geq 130 \mathrm{mmHg})$ & $211(12.7)$ & $60(3.8)$ \\
High DBP $(\geq 185 \mathrm{mmHg})$ & $48(2.9)$ & $134(8.5)$ \\
High BP $($ high SBP, or high DBP) & $232(14.0)$ & $6(0.4)$ \\
MS (IOTF) & $14(0.8)$ & $9(0.6)$ \\
MS ( $\geq 1 \mathrm{SD})$ & $17(1.0)$ & \\
\hline
\end{tabular}

Data are presented as mean \pm SD or counts (\%). BMI, body mass index; zBMI, z-score of BMI; \%E, percentage of total energy intake; IOTF, International Obesity Task Force; SD, standard deviation; LDL, low-density lipoprotein cholesterol; HDL, high-density lipoprotein cholesterol; TG, triglyceride; Glu, fasting glucose, SBP and DBP, systolic and diastolic blood pressure; MS, metabolic syndrome. Metabolic syndrome was determined as overweight (IOTF, or $\geq 1 \mathrm{SD}$ ) plus two or more risks of low HDL, high TG, high fasting glucose, and high BP.

Categories based on quintiles of sugars intake were positively associated with Glu level and z-score of metabolic syndrome with adjustment for confounders including TEI, and zBMI $\left(P_{\text {trend }}<0.001\right.$, and $P_{\text {trend }} \leq 0.02$, respectively; Table 2); differences between the highest and lowest intakes were $1.0-1.3 \mathrm{mg} / \mathrm{dL}$ in Glu, and 0.06-0.12 in z-score of metabolic syndrome. Categorized added and free sugars intakes were positively associated with systolic BP level $\left(P_{\text {trend }} \leq 0.025,1.7-2.3 \mathrm{mmHg}\right.$ ).

High intakes of added or free sugars were not significantly associated with overweight or other risks, except for added sugars intake $\geq 10 \% \mathrm{E}$ for Glu $\geq 100 \mathrm{mg} / \mathrm{dL}$ (OR 1.51, 95\% confidence interval (CI) $1.04-2.19, p=0.031$; Table 3). For the sensitivity analysis, when high risks were defined as the highest $10 \%$ of risk levels, only ORs of high added sugars $\geq 5 \% \mathrm{E}$ and $\geq 10 \% \mathrm{E}$ and free sugars $\geq 10 \% \mathrm{E}$ with Glu were significant $(n=3242 ; p \leq 0.040)$. Additionally, the OR of added sugar $\geq 5 \% \mathrm{E}$ with high LDL and the ORs of free sugars $\geq 5 \% \mathrm{E}$ with high LDL and high SBP were significant ( $p=0.017-0.044)$; but the ORs for metabolic syndrome were insignificant. When analyzing the data separately by gender ( $n$ for males $=1659$, and for females $=1583$ ), similar ORs were obtained (data not shown). The association between added sugars intake $\geq 10 \% \mathrm{E}$ and high Glu retained their significance even when the analysis was restricted to the students who responded to the BDHQ by themselves $(n=1626$; OR $1.49 ; 95 \%$ CI $1.03-2.15, p=0.033$ ). 
Table 2. Least square means of risk parameters according to quintile categories of sugars intake.

\begin{tabular}{|c|c|c|c|c|c|c|}
\hline & Q1 & Q2 & Q3 & Q4 & Q5 & $P_{\text {trend }}$ \\
\hline Added sugars, $n$ & 647 & 649 & 650 & 648 & 648 & \\
\hline$\% \mathrm{E}$ & $3.36 \pm 0.83$ & $5.37 \pm 0.49$ & $6.99 \pm 0.53$ & $8.89 \pm 0.71$ & $14.01 \pm 3.87$ & \\
\hline zBMI & 0.11 & 0.10 & 0.03 & 0.01 & 0.08 & 0.289 \\
\hline $\mathrm{LDL}, \mathrm{mg} / \mathrm{dL}$ & 88.8 & 90.1 & 89.8 & 89.8 & 90.2 & 0.393 \\
\hline $\mathrm{HDL}, \mathrm{mg} / \mathrm{dL}$ & 67.3 & 67.7 & 68.4 & 67.7 & 67.2 & 0.883 \\
\hline $\mathrm{TG}, \mathrm{mg} / \mathrm{dL}$ & 58.3 & 59.1 & 57.2 & 59.6 & 59.1 & 0.587 \\
\hline Glu, mg/dL & 89.5 & 89.7 & 89.9 & 90.5 & 90.8 & $<0.001$ \\
\hline $\mathrm{SBP}, \mathrm{mmHg}$ & 112.7 & 114.4 & 114.1 & 114.9 & 115.0 & $<0.001$ \\
\hline $\mathrm{DBP}, \mathrm{mmHg}$ & 67.8 & 68.2 & 67.8 & 68.3 & 68.5 & 0.152 \\
\hline zMS & -0.06 & 0.00 & -0.04 & 0.04 & 0.06 & $<0.001$ \\
\hline Free sugars, $n$ & 647 & 649 & 649 & 649 & 648 & \\
\hline$\% \mathrm{E}$ & $3.73 \pm 0.96$ & $5.97 \pm 0.56$ & $7.78 \pm 0.59$ & $9.9 \pm 0.76$ & $15.58 \pm 4.28$ & \\
\hline zBMI & 0.13 & 0.07 & 0.05 & -0.01 & 0.09 & 0.277 \\
\hline $\mathrm{LDL}, \mathrm{mg} / \mathrm{dL}$ & 89.0 & 88.9 & 90.1 & 90.1 & 90.6 & 0.113 \\
\hline $\mathrm{HDL}, \mathrm{mg} / \mathrm{dL}$ & 67.2 & 68.2 & 68.3 & 67.7 & 67.0 & 0.513 \\
\hline $\mathrm{TG}, \mathrm{mg} / \mathrm{dL}$ & 58.7 & 57.3 & 58.4 & 60.9 & 58.1 & 0.532 \\
\hline Glu, mg/dL & 89.6 & 89.5 & 90.2 & 90.3 & 90.8 & $<0.001$ \\
\hline $\mathrm{SBP}, \mathrm{mmHg}$ & 113.0 & 114.7 & 114.0 & 114.7 & 114.7 & 0.025 \\
\hline $\mathrm{DBP}, \mathrm{mmHg}$ & 67.7 & 68.6 & 67.9 & 67.8 & 68.6 & 0.404 \\
\hline zMS & -0.05 & -0.01 & -0.02 & 0.02 & 0.05 & 0.001 \\
\hline
\end{tabular}

Data are presented as mean intake \pm standard deviation. \%E, percentage of total energy intake; $z B M I, z$-score of body mass index LDL, low-density lipoprotein cholesterol; HDL, high-density lipoprotein cholesterol; TG, triglyceride; Glu; fasting glucose; SBP, and DBP, systolic and diastolic blood pressure; zMS, z-score of metabolic syndrome is calculated as the mean of the z-scores of BMI, HDL (inversed), TG, Glu, SBP, and DBP. Least square means were adjusted for age, gender, sleeping duration, number of siblings, single parent, physical activity, total energy, fat, and total dietary fiber. Parameters other than zBMI were additionally adjusted for zBMI. $P_{\text {trend }}$ indicates the tests of simple linear trends of the risk levels among the ranked categories of sugars intake. 
Table 3. Odds ratios of high sugars intake for overweight, high LDL, TG, Glu, SBP, DBP or BP, low HDL, and MS.

\begin{tabular}{|c|c|c|c|c|c|c|c|c|c|c|}
\hline & \multicolumn{5}{|c|}{ Added Sugars Intake } & \multicolumn{5}{|c|}{ Free Sugars Intake } \\
\hline & Low (ref.) & High & OR & $(95 \% \mathrm{CI})$ & $p$ & Low (ref.) & High & OR & $(95 \% \mathrm{CI})$ & $p$ \\
\hline Cutoff, $5 \% \mathrm{E}$ & 822 & 2420 & & & & 632 & 2610 & & & \\
\hline Overweight (IOTF) & $86(10.5)$ & $216(8.9)$ & 0.95 & $(0.72,1.26)$ & 0.744 & $67(10.6)$ & $235(9.0)$ & 0.97 & $(0.71,1.31)$ & 0.819 \\
\hline Overweight ( $\geq 1 \mathrm{SD})$ & $154(18.7)$ & $418(17.3)$ & 0.98 & $(0.79,1.21)$ & 0.841 & $119(18.8)$ & $453(17.4)$ & 0.98 & $(0.78,1.24)$ & 0.874 \\
\hline High LDL & $59(7.2)$ & $229(9.5)$ & 1.29 & $(0.94,1.76)$ & 0.112 & $44(7.0)$ & $244(9.3)$ & 1.32 & $(0.94,1.87)$ & 0.113 \\
\hline Low HDL & $6(0.7)$ & $22(0.9)$ & 1.38 & $(0.53,3.58)$ & 0.511 & $5(0.8)$ & $23(0.9)$ & 1.26 & $(0.46,3.5)$ & 0.653 \\
\hline High TG & $21(2.6)$ & $40(1.7)$ & 0.79 & $(0.45,1.41)$ & 0.429 & $17(2.7)$ & $44(1.7)$ & 0.78 & $(0.43,1.43)$ & 0.419 \\
\hline High Glu & $32(3.9)$ & $121(5.0)$ & 1.25 & $(0.83,1.90)$ & 0.291 & $27(4.3)$ & $126(4.8)$ & 1.11 & $(0.71,1.73)$ & 0.641 \\
\hline High DBP & $26(3.2)$ & $82(3.4)$ & 1.10 & $(0.69,1.75)$ & 0.704 & $17(2.7)$ & $91(3.5)$ & 1.36 & $(0.79,2.34)$ & 0.273 \\
\hline High BP & $92(11.2)$ & $274(11.3)$ & 1.15 & $(0.88,1.51)$ & 0.300 & $71(11.2)$ & $295(11.3)$ & 1.16 & $(0.87,1.56)$ & 0.309 \\
\hline MS (IOTF) & $6(0.7)$ & $14(0.6)$ & 1.24 & $(0.36,4.28)$ & 0.738 & $5(0.8)$ & $15(0.6)$ & 1.22 & $(0.34,4.41)$ & 0.765 \\
\hline MS ( $\geq 1$ SD) & $6(0.7)$ & $20(0.8)$ & 1.53 & $(0.51,4.60)$ & 0.452 & $5(0.8)$ & $21(0.8)$ & 1.53 & $(0.47,4.94)$ & 0.481 \\
\hline Cutoff, $10 \% \mathrm{E}$ & 2551 & 691 & & & & 2319 & 923 & & & \\
\hline Overweight (IOTF) & $237(9.3)$ & $65(9.4)$ & 1.05 & $(0.78,1.41)$ & 0.763 & $216(9.3)$ & $86(9.3)$ & 1.03 & $(0.79,1.35)$ & 0.830 \\
\hline Overweight ( $\geq 1 \mathrm{SD}$ ) & $452(17.7)$ & $120(17.4)$ & 0.99 & $(0.79,1.24)$ & 0.918 & $417(18)$ & $155(16.8)$ & 0.93 & $(0.75,1.14)$ & 0.460 \\
\hline High LDL & $213(8.3)$ & 75 (10.9) & 1.26 & $(0.95,1.68)$ & 0.113 & $195(8.4)$ & $93(10.1)$ & 1.17 & $(0.89,1.52)$ & 0.263 \\
\hline Low HDL & $22(0.9)$ & $6(0.9)$ & 1.04 & $(0.41,2.63)$ & 0.942 & $21(0.9)$ & $7(0.8)$ & 0.86 & $(0.36,2.08)$ & 0.744 \\
\hline High Glu & $109(4.3)$ & $44(6.4)$ & 1.51 & $(1.04,2.19)$ & 0.031 & $102(4.4)$ & $51(5.5)$ & 1.28 & $(0.90,1.82)$ & 0.171 \\
\hline High SBP & $243(9.5)$ & $60(8.7)$ & 0.94 & $(0.69,1.28)$ & 0.683 & $222(9.6)$ & $81(8.8)$ & 0.97 & $(0.73,1.28)$ & 0.826 \\
\hline High DBP & $88(3.4)$ & $20(2.9)$ & 0.85 & $(0.51,1.41)$ & 0.529 & 77 (3.3) & $31(3.4)$ & 1.03 & $(0.67,1.59)$ & 0.891 \\
\hline High BP & 293 (11.5) & $73(10.6)$ & 0.94 & $(0.70,1.24)$ & 0.642 & 265 (11.4) & $101(10.9)$ & 1.00 & $(0.78,1.29)$ & 0.999 \\
\hline MS (IOTF) & $18(0.7)$ & $2(0.3)$ & 0.61 & $(0.12,3.12)$ & 0.551 & $17(0.7)$ & $3(0.3)$ & 0.63 & $(0.15,2.63)$ & 0.528 \\
\hline MS ( $\geq 1 \mathrm{SD})$ & $22(0.9)$ & $4(0.6)$ & 0.95 & $(0.29,3.07)$ & 0.930 & $20(0.9)$ & $6(0.7)$ & 1.04 & $(0.37,2.93)$ & 0.939 \\
\hline
\end{tabular}

Data are presented as $n(\%) . \% \mathrm{E}$, percentage of total energy intake; IOTF, International Obesity Task Force; SD, standard deviation; LDL, low-density lipoprotein cholesterol; HDL, high-density lipoprotein cholesterol; TG, triglyceride; Glu, fasting glucose; BP, blood pressure; MS, metabolic syndrome. MS was determined as overweight (IOTF or $\geq 1 \mathrm{SD}$ ) plus two or physical activity, total energy, fat, and total dietary fiber. ORs, for cardiometabolic risks other than overweight, were additionally adjusted for a z-score of BMI. 


\section{Discussion}

Ranked variables of added and free sugars intake in Japanese secondary school students were associated with their plasma glucose level, BP level, and metabolic syndrome score as continuous variables. When using dichotomous variables, high intake of added sugars $\geq 10 \% \mathrm{E}$ was also significantly associated with high plasma glucose $\geq 100 \mathrm{mg} / \mathrm{dL}$, but other associations of high sugars intake were not significant, even when using added or free sugars intake, and using overweight prevalence based on two different definitions.

Reports on sugars intake in Japanese adolescents are scarce. Dietary records of 915 Japanese primary and secondary school students aged $8-14$ years revealed that students consumed $51.7-52.5 \%$ of energy from carbohydrates, which included total sugars (12.3-12.8\%E) and free sugars (5.8-6.0\%E) [32]. The sugars intake estimated from dietary records is lower than the sugars intake in this current study in which students were aged 13-14 years. Even though Japanese adolescents could consume more sugars than children, mean added or free sugars intake of Japanese secondary school students did not exceed 10\%E, unlike those of European and American adolescents [18,42,43].

Higher consumption of SSBs was associated with higher fasting glucose in the UK adolescents [44] and high homeostasis model assessment-insulin resistance (HOMA-IR) in the US adolescents [45]. In a cross-sectional study of the US adolescents aged 12-19 years, however, added sugars intake was not significantly associated with glucose, insulin, or HOMA-IR [46]. Although we did not measure insulin levels and HOMA-IR, we demonstrated the association between added or free sugars and fasting glucose level. The associations were not sufficient to identify any adolescent with a high risk because only the OR of high added sugars intake $\geq 10 \% \mathrm{E}$ was significant.

A possible mechanism of the association between high sugars intake and high BP is the elevation of uric acid intermediates. Fructose consumption induces purine degradation [47], and a slight elevation of blood glucose (within the normal range) enhances uric acid reabsorption [48]. Although uric acid levels were not measured in this study, previous cross-sectional studies showed that intake of SSBs and sugars was significantly associated with uric acid level in the US adolescents [46,49]. However, the results of the association between sugars intake and BP are inconsistent. The association of the $\mathrm{z}$-score of SBP and SSBs in studies using data from the US National Health and Nutrition Examination Survey was significant, while studies using the continuous variable of BP with SSBs [45] or studies on high BP with added sugars [46] showed a non-significant association. In our study, the continuous variable of BP was significantly associated with sugars intake, but the ORs for high BP were not significant.

Like other risks, metabolic syndrome score as a continuous variable was significantly associated with sugars intake in this study; but the ORs were not significant. The definition of metabolic syndrome proposed by the IDF includes central adiposity instead of total adiposity BMI as an essential item. There is controversy regarding whether BMI, or central adiposity is a stronger predictor of cardiovascular risks [50]. We did not measure the students' waist circumference, but we determined the associations using prevalence based on the two definitions of overweight, IOTF and $\geq 1 \mathrm{SD}$, because Asians have less BMI, but similar associations with cardiovascular risks [15,51]. Several studies on Asian adults showed that BMI is associated with diabetes, hypertension, metabolic syndrome, and central obesity indices [50-53]. Hence, the results of this study indicate that the association between sugars intake and metabolic syndrome may be weak in Japanese adolescents.

Another possible explanation for low ORs of sugars intake for metabolic syndrome is the difference in the ranges of sugars intake between Japan and European or American countries [18,42,43]. Adolescents in this study consumed 7.6-7.9\%E of added sugars and $8.4-8.8 \% \mathrm{E}$ of free sugars. Children and adolescents in Portugal [54], Spain [55], Slovenia [56], Colombia, and Ecuador [43] had a mean intake of $9.5-11.6 \% \mathrm{E}$ and $9.8-10.1 \% \mathrm{E}$, respectively. The intake in this study was lower than that in previous studies; in particular in the Netherlands [57], the UK [58], the US [42], Argentina, Brazil, Chile, Costa Rica, Peru, and Venezuela [43] (12.9-18.4\%E and 17.6-20.7\%E, respectively). Most literatures that reported significant associations of cardiometabolic risks came from the US [45,46,49], where the prevalence of metabolic syndrome based on the IDF definition, i.e., $5.2-9.5 \%$ at age 14 years $[59,60]$ was 
higher than that in the current study. In the population with low intake and low prevalence, we could not find significant ORs.

Previous studies on Asian adolescents did not show significant associations between intake of sugars or SSBs and adiposity $[23,24,61]$. Since sugars intake is required to gain weight from excess energy intake [7], the association between sugars intake and obesity may be confounded by energy intake. Adjusting for confounding factors is too complicated. A cross-sectional study evaluating any association with obesity is prone to biases in an unexpected direction. In order to examine the associations with adiposity, a prospective cohort study or a randomized control trial should be implemented [1,62].

A large sample size, one of the strengths of this study, revealed the associations of added or free sugars intake with Glu, SBP, and metabolic syndrome score. However the ORs for metabolic syndrome or most of other risks were not significant even with a large sample size, which is comparable to those of other studies on Asian adolescents [24,25]. Other than BMI, we used metabolic variables that might be a rare complicated confounder of energy intake. Specifically, we analyzed the data while restricting the data to fasting blood samples, even though plasma glucose levels returned to normal after only $2 \mathrm{~h}$ in healthy adolescents. In this sample, the mean plasma glucose for students with and without breakfast was $90.03 \mathrm{mg} / \mathrm{dL}$ and $90.16 \mathrm{mg} / \mathrm{dL}$, respectively; this is the second strength of this study. However, one limitation in this study was that BDHQ was a self-administered questionnaire. The students may respond to the questionnaire with knowledge about a healthy lifestyle. This desirability bias might weaken the true association. Estimation of sugars intake from the BDHQ might be a second limitation. Added and free sugars intake had a plausible range in Japanese participants, but the results warrant further studies with a different sample and other dietary assessment.

\section{Conclusions}

Categorized intake of added and free sugars was associated with the continuous variables of cardiovascular risk levels in Japanese adolescents whose mean intake was less than $10 \% \mathrm{E}$, after adjustment for confounders including energy intake and zBMI. When using dichotomous variables, however, we are unable to identify adolescents with a high multiple risk based on high sugars intake. This is because we did not find significant associations except that between high added sugars intake and high fasting glucose. In particular, we could not find significant ORs for metabolic syndrome under any situation, such as in stratified analysis by gender, using different definitions of metabolic syndrome, or in a restricted sample. We recommend a reduction in the amount of added or free sugars in Japanese adolescents with high intake levels. For public health concerns, recommendation of added sugars intake $<10 \% \mathrm{E}$ should be considered to prevent glucose intolerance in adolescents. However, further recommendation to lower added sugars intake $<5 \% \mathrm{E}$ was not supported by this study's findings.

Author Contributions: M.O. designed the study, managed data collection, statistically analyzed the collected data, and prepared the manuscript. A.F. estimated sugar and nutrient intake and assisted in the writing of the manuscript. S.S. provided the concept for this analysis. All authors contributed to its revision and approved the final version. All authors have read and agreed to the published version of the manuscript.

Funding: We received no financial support for designing the study and collecting data. Manuscript preparation and submission were supported by Japan Society for the Promotion of Science KAKENHI Grant Number JP18K10085.

Acknowledgments: We thank the staff members of Shunan City and school teachers for their help in the survey, especially Masaru Fukuya for his contribution to the start-up of the conjoint health program. We appreciate Kunitsugu, Sugiyama, and Yoshitake for their support in data collection.

Conflicts of Interest: The authors had no conflict of interest to declare. 


\section{References}

1. Te Morenga, L.; Mallard, S.; Mann, J. Dietary sugars and body weight: Systematic review and meta-analyses of randomised controlled trials and cohort studies. BMJ 2012, 346, e7492. [CrossRef]

2. Te Morenga, L.A.; Howatson, A.J.; Jones, R.M.; Mann, J. Dietary sugars and cardiometabolic risk: Systematic review and meta-analyses of randomized controlled trials of the effects on blood pressure and lipids. Am. J. Clin. Nutr. 2014, 100, 65-79. [CrossRef]

3. Sheiham, A.; James, W.P. A reappraisal of the quantitative relationship between sugar intake and dental caries: The need for new criteria for developing goals for sugar intake. BMC Public Health 2014, 14, 863. [CrossRef] [PubMed]

4. World Health Organization. Guideline: Sugars Intake for Adults and Children. In Guideline: Sugars Intake for Adults and Children; World Health Organization, Ed.; World Health Organization: Geneva, Switzerland, 2015.

5. Otten, J.J.; Hellwig, J.P.; Meyers, L.D. (Eds.) Dietary Reference Intakes: The Essential Guide to Nutrient Requirements; The National Academies Press: Washington, DC, USA, 2006.

6. U.S. Department of Health and Human Services; U.S. Department of Agruiculture. 2015-2020 Dietary Guidelines for Americans, 8th ed.; U.S. Department of Agriculture: Washington, DC, USA, 2015.

7. Vos, M.B.; Kaar, J.L.; Welsh, J.A.; Van Horn, L.V.; Feig, D.I.; Anderson, C.A.M.; Patel, M.J.; Cruz Munos, J.; Krebs, N.F.; Xanthakos, S.A.; et al. Added Sugars and Cardiovascular Disease Risk in Children: A Scientific Statement From the American Heart Association. Circulation 2017, 135, e1017-e1034. [CrossRef] [PubMed]

8. Yamagishi, K.; Iso, H. The criteria for metabolic syndrome and the national health screening and education system in Japan. Epidemiol. Health 2017, 39, e2017003. [CrossRef]

9. OECD. Obesity Update 2017. Available online: http://www.oecd.org/health/obesity-update.htm (accessed on 9 April 2020).

10. Mukai, N.; Hata, J.; Hirakawa, Y.; Ohara, T.; Yoshida, D.; Nakamura, U.; Kitazono, T.; Ninomiya, T. Trends in the prevalence of type 2 diabetes and prediabetes in a Japanese community, 1988-2012: The Hisayama Study. Diabetol. Int. 2019, 10, 198-205. [CrossRef] [PubMed]

11. Ministry of Education Culture Sports Science and Technology. School Health Survey Report 2018; Ministry of Education Culture Sports Science and Technology: Tokyo, Japan, 2019.

12. Cameron, A.J.; Sicree, R.A.; Zimmet, P.Z.; Alberti, K.G.; Tonkin, A.M.; Balkau, B.; Tuomilehto, J.; Chitson, P.; Shaw, J.E. Cut-points for waist circumference in Europids and South Asians. Obesity 2010, 18, 2039-2046. [CrossRef] [PubMed]

13. Tillin, T.; Sattar, N.; Godsland, I.F.; Hughes, A.D.; Chaturvedi, N.; Forouhi, N.G. Ethnicity-specific obesity cut-points in the development of Type 2 diabetes-A prospective study including three ethnic groups in the United Kingdom. Diabet. Med. 2015, 32, 226-234. [CrossRef]

14. Paul, S.K.; Owusu Adjah, E.S.; Samanta, M.; Patel, K.; Bellary, S.; Hanif, W.; Khunti, K. Comparison of body mass index at diagnosis of diabetes in a multi-ethnic population: A case-control study with matched non-diabetic controls. Diabet. Obest. Metab. 2017, 19, 1014-1023. [CrossRef]

15. WHO Expert Consultation. Appropriate body-mass index for Asian populations and its implications for policy and intervention strategies. Lancet 2004, 363, 157-163. [CrossRef]

16. OECD; FAO. OECD-FA Agricultural Outlook; 2019-2028; OECD Publishing: Paris, France; Food and Agriculture Organization of the United Nations: Rome, Italy, 2019.

17. Guthrie, J.F.; Morton, J.F. Food sources of added sweeteners in the diets of Americans. J. Am. Diet. Assoc. 2000, 100, 43-51. [CrossRef]

18. Azais-Braesco, V.; Sluik, D.; Maillot, M.; Kok, F.; Moreno, L.A. A review of total \& added sugar intakes and dietary sources in Europe. Nutr. J. 2017, 16, 6. [CrossRef] [PubMed]

19. Popkin, B.M.; Hawkes, C. Sweetening of the global diet, particularly beverages: Patterns, trends, and policy responses. Lancet Diabet. Endocrinol. 2016, 4, 174-186. [CrossRef]

20. Ministry of Agriculture, Forestry and Fisheries. Washoku: Traditional Dietary Cultures of the Japanese; Ministry of Agriculture, Forestry and Fisheries: Tokyo, Japan, 2013.

21. Lee, H.S.; Kwon, S.O.; Lee, Y. Weight status and dietary factors associated with sugar-sweetened beverage intake among Korean children and adolescents-Korea National Health and Nutrition Examination Survey, 2008-2011. Clin. Nutr. Res. 2013, 2, 135-142. [CrossRef] [PubMed] 
22. Shang, X.W.; Liu, A.L.; Zhang, Q.; Hu, X.Q.; Du, S.M.; Ma, J.; Xu, G.F.; Li, Y.; Guo, H.W.; Du, L.; et al. Report on childhood obesity in China (9): Sugar-sweetened beverages consumption and obesity. Biomed. Environ. Sci. 2012, 25, 125-132. [CrossRef] [PubMed]

23. Shikanai, S.; Koung Ry, L.; Takeichi, H.; Emiko, S.; San, P.; Sarukura, N.; Kamoshita, S.; Yamamoto, S. Sugar intake and body weight in Cambodian and Japanese children. J. Med. Invest. 2014, 61, 72-78. [CrossRef]

24. Hur, Y.I.; Park, H.; Kang, J.H.; Lee, H.A.; Song, H.J.; Lee, H.J.; Kim, O.H. Associations between sugar intake from different food sources and adiposity or cardio-metabolic risk in childhood and adolescence: The Korean Child-Adolescent Cohort Study. Nutrients 2015, 8, 20. [CrossRef]

25. Mirmiran, P.; Ziadlou, M.; Karimi, S.; Hosseini-Esfahani, F.; Azizi, F. The association of dietary patterns and adherence to WHO healthy diet with metabolic syndrome in children and adolescents: Tehran lipid and glucose study. BMC Public Health 2019, 19, 1457. [CrossRef]

26. Fattore, E.; Botta, F.; Agostoni, C.; Bosetti, C. Effects of free sugars on blood pressure and lipids: A systematic review and meta-analysis of nutritional isoenergetic intervention trials. Am. J. Clin. Nutr. 2017, 105, 42-56. [CrossRef]

27. Okuda, M.; Sugiyama, S.; Kunitsugu, I.; Hinoda, Y.; Shirabe, K.; Yoshitake, N.; Hobara, T. Use of body mass index and percentage overweight cutoffs to screen Japanese children and adolescents for obesity-related risk factors. J. Epidemiol. 2010, 20, 46-53. [CrossRef]

28. Shinozaki, K.; Okuda, M.; Sasaki, S.; Kunitsugu, I.; Shigeta, M. Dietary fiber consumption decreases the risks of overweight and hypercholesterolemia in Japanese children. Ann. Nutr. Metab. 2015, 67, 58-64. [CrossRef] [PubMed]

29. Okuda, M.; Sasaki, S.; Bando, N.; Hashimoto, M.; Kunitsugu, I.; Sugiyama, S.; Terao, J.; Hobara, T. Carotenoid, tocopherol, and fatty acid biomarkers and dietary intake estimated by using a brief self-administered diet history questionnaire for older Japanese children and adolescents. J. Nutr. Sci. Vitaminol. 2009, 55, 231-241. [CrossRef]

30. Okuda, M.; Asakura, K.; Sasaki, S. Protein intake estimated from brief-type self-administered diet history questionnaire and urinary urea nitrogen level in adolescents. Nutrients 2019, 11, 319. [CrossRef] [PubMed]

31. Kobayashi, S.; Honda, S.; Murakami, K.; Sasaki, S.; Okubo, H.; Hirota, N.; Notsu, A.; Fukui, M.; Date, C. Both Comprehensive and Brief Self-Administered Diet History Questionnaires Satisfactorily Rank Nutrient intakes in Japanese Adults. J. Epidemiol. 2012, 22, 151-159. [CrossRef]

32. Fujiwara, A.; Murakami, K.; Asakura, K.; Uechi, K.; Sugimoto, M.; Wang, H.C.; Masayasu, S.; Sasaki, S. Estimation of starch and sugar intake in a Japanese population based on a newly dveloped food composition database. Nutrients 2018, 10, 1474. [CrossRef]

33. Fujiwara, A.; Murakami, K.; Sasaki, S. Relative validity of starch and sugar intake in Japanese adults as estimated with comprehensive and brief self-administered diet history questionnaires. J. Epidemiol. 2019. [CrossRef] [PubMed]

34. Inokuchi, M.; Hasegawa, T.; Anzo, M.; Matsuo, N. Standardized centile curves of body mass index for Japanese children and adolescents based on the 1978-1981 national survey data. Ann. Hum. Biol. 2006, 33, 444-453. [CrossRef] [PubMed]

35. Cole, T.J.; Bellizzi, M.C.; Flegal, K.M.; Dietz, W.H. Establishing a standard definition for child overweight and obesity worldwide: International survey. BMJ 2000, 320, 1240-1243. [CrossRef] [PubMed]

36. De Onis, M.; Onyango, A.W.; Borghi, E.; Siyam, A.; Nishida, C.; Siekmann, J. Development of a WHO growth reference for school-aged children and adolescents. Bull. World Health Organ. 2007, 85, 660-667. [CrossRef]

37. Kinoshita, M.; Yokote, K.; Arai, H.; Iida, M.; Ishigaki, Y.; Ishibashi, S.; Umemoto, S.; Egusa, G.; Ohmura, H.; Okamura, T.; et al. Japan Atherosclerosis Society (JAS) guidelines for prevention of atherosclerotic cardiovascular diseases 2017. J. Atheroscler. Thromb. 2018, 25, 846-984. [CrossRef]

38. Zimmet, P.; Alberti, K.G.; Kaufman, F.; Tajima, N.; Silink, M.; Arslanian, S.; Wong, G.; Bennett, P.; Shaw, J.; Caprio, S.; et al. The metabolic syndrome in children and adolescents-An IDF consensus report. Pediatr Diabetes 2007, 8, 299-306. [CrossRef]

39. Franks, P.W.; Ekelund, U.; Brage, S.; Wong, M.Y.; Wareham, N.J. Does the association of habitual physical activity with the metabolic syndrome differ by level of cardiorespiratory fitness? Diabetes Care 2004, 27, 1187-1193. [CrossRef] [PubMed]

40. Hishida, A.; Sasaki, S. Dietary Reference Intakes for Japanese, 2015; Daiichi-Shuppan Co. Ltd.: Tokyo, Japan, 2014. 
41. Cruz, M.L.; Weigensberg, M.J.; Huang, T.T.; Ball, G.; Shaibi, G.Q.; Goran, M.I. The metabolic syndrome in overweight Hispanic youth and the role of insulin sensitivity. J. Clin. Endocrinol. Metab. 2004, 89, 108-113. [CrossRef] [PubMed]

42. Bailey, R.L.; Fulgoni, V.L.; Cowan, A.E.; Gaine, P.C. Sources of added sugars in young children, adolescents, and adults with low and high intakes of added sugars. Nutrients 2018, 10, 102. [CrossRef] [PubMed]

43. Fisberg, M.; Kovalskys, I.; Gomez, G.; Rigotti, A.; Sanabria, L.Y.C.; Garcia, M.C.Y.; Torres, R.G.P.; Herrera-Cuenca, M.; Zimberg, I.Z.; Koletzko, B.; et al. Total and added sugar intake: Assessment in eight Latin American countries. Nutrients 2018, 10, 389. [CrossRef] [PubMed]

44. Seferidi, P.; Millett, C.; Laverty, A.A. Sweetened beverage intake in association to energy and sugar consumption and cardiometabolic markers in children. Pediatr. Obes. 2018, 13, 195-203. [CrossRef]

45. Bremer, A.A.; Auinger, P.; Byrd, R.S. Relationship between insulin resistance-associated metabolic parameters and anthropometric measurements with sugar-sweetened beverage intake and physical activity levels in US adolescents: Findings from the 1999-2004 National Health and Nutrition Examination Survey. Arch. Pediatr. Adolesc. Med. 2009, 163, 328-335. [CrossRef]

46. Rodriguez, L.A.; Madsen, K.A.; Cotterman, C.; Lustig, R.H. Added sugar intake and metabolic syndrome in US adolescents: Cross-sectional analysis of the National Health and Nutrition Examination Survey 2005-2012. Public. Health Nutr. 2016, 19, 2424-2434. [CrossRef]

47. Fox, I.H.; Kelley, W.N. Studies on the mechanism of fructose-induced hyperuricemia in man. Metabolism 1972, 21, 713-721. [CrossRef]

48. Wei, F.; Chang, B.; Yang, X.; Wang, Y.; Chen, L.; Li, W.D. Serum uric acid levels were dynamically coupled with hemoglobin A1c in the development of type 2 diabetes. Sci. Rep. 2016, 6, 28549. [CrossRef]

49. Nguyen, S.; Choi, H.K.; Lustig, R.H.; Hsu, C.Y. Sugar-sweetened beverages, serum uric acid, and blood pressure in adolescents. J. Pediatr. 2009, 154, 807-813. [CrossRef] [PubMed]

50. Decoda Study, G.; Nyamdorj, R.; Qiao, Q.; Lam, T.H.; Tuomilehto, J.; Ho, S.Y.; Pitkaniemi, J.; Nakagami, T.; Mohan, V.; Janus, E.D.; et al. BMI compared with central obesity indicators in relation to diabetes and hypertension in Asians. Obesity 2008, 16, 1622-1635. [CrossRef] [PubMed]

51. Vazquez, G.; Duval, S.; Jacobs, D.R., Jr.; Silventoinen, K. Comparison of body mass index, waist circumference, and waist/hip ratio in predicting incident diabetes: A meta-analysis. Epidemiol. Rev. 2007, 29, 115-128. [CrossRef] [PubMed]

52. Wang, F.; Wu, S.; Song, Y.; Tang, X.; Marshall, R.; Liang, M.; Wu, Y.; Qin, X.; Chen, D.; Hu, Y. Waist circumference, body mass index and waist to hip ratio for prediction of the metabolic syndrome in Chinese. Nutr. Metab. Cardiovasc. Dis. 2009, 19, 542-547. [CrossRef] [PubMed]

53. Qiao, Q.; Nyamdorj, R. Is the association of type II diabetes with waist circumference or waist-to-hip ratio stronger than that with body mass index? Eur. J. Clin. Nutr. 2010, 64, 30-34. [CrossRef]

54. Marinho, A.R.; Severo, M.; Correia, D.; Lobato, L.; Vilela, S.; Oliveira, A.; Ramos, E.; Torres, D.; Lopes, C. Total, added and free sugar intakes, dietary sources and determinants of consumption in Portugal: The National Food, Nutrition and Physical Activity Survey (IAN-AF 2015-2016). Public Health Nutr. 2020, 23, 869-881. [CrossRef]

55. Ruiz, E.; Rodriguez, P.; Valero, T.; Avila, J.M.; Aranceta-Bartrina, J.; Gil, A.; Gonzalez-Gross, M.; Ortega, R.M.; Serra-Majem, L.; Varela-Moreiras, G. Dietary intake of individual (free and intrinsic) sugars and food sources in the Spanish population: Findings from the ANIBES Study. Nutrients 2017, 9, 275. [CrossRef]

56. Zupanic, N.; Hristov, H.; Gregoric, M.; Blaznik, U.; Delfar, N.; Korousic Seljak, B.; Ding, E.L.; Fidler Mis, N.; Pravst, I. Total and free sugars consumption in a Slovenian population representative sample. Nutrients 2020, 12, 1729. [CrossRef]

57. Sluik, D.; Van Lee, L.; Engelen, A.I.; Feskens, E.J. Total, free, and added sugar consumption and adherence to guidelines: The Dutch National Food Consumption Survey 2007-2010. Nutrients 2016, 8, 70. [CrossRef]

58. Amoutzopoulos, B.; Steer, T.; Roberts, C.; Collins, D.; Page, P. Free and added sugar consumption and adherence to guidelines: The UK National Diet and Nutrition Survey (2014/15-2015/16). Nutrients 2020, 12, 393. [CrossRef]

59. Ford, E.S.; Li, C.; Zhao, G.; Pearson, W.S.; Mokdad, A.H. Prevalence of the metabolic syndrome among U.S. adolescents using the definition from the International Diabetes Federation. Diabetes Care 2008, 31, 587-589. [CrossRef] [PubMed] 
60. Studies to Treat or Prevent Pediatric Type 2 Diabetes Prevention Study Group. Prevalence of the metabolic syndrome among a racially/ethnically diverse group of U.S. eighth-grade adolescents and associations with fasting insulin and homeostasis model assessment of insulin resistance levels. Diabetes Care 2008, 31, 2020-2025. [CrossRef]

61. Ha, K.; Chung, S.; Lee, H.S.; Kim, C.I.; Joung, H.; Paik, H.Y.; Song, Y. Association of dietary sugars and sugar-sweetened beverage intake with obesity in Korean children and adolescents. Nutrients 2016, 8, 31. [CrossRef]

62. Malik, V.S.; Pan, A.; Willett, W.C.; Hu, F.B. Sugar-sweetened beverages and weight gain in children and adults: A systematic review and meta-analysis. Am. J. Clin. Nutr. 2013, 98, 1084-1102. [CrossRef] [PubMed]

(C) 2020 by the authors. Licensee MDPI, Basel, Switzerland. This article is an open access article distributed under the terms and conditions of the Creative Commons Attribution (CC BY) license (http://creativecommons.org/licenses/by/4.0/). 